\title{
Assessment of Sugarcane Genotypes for Red Rot Resistance and Antifungal Activity of Rhizosphere Microbiota against Colletotricum falcatum
}

\author{
Saman Aslam ${ }^{1}$, M. Imran Hamid ${ }^{1 *}$, M. Usman Ghazanfar ${ }^{1}$ and Naeem Akhtar ${ }^{2}$ \\ ${ }^{1}$ Department of Plant Pathology, College of Agriculture, University of Sargodha, Sargodha, 40100, Pakistan \\ ${ }^{2}$ Department of Plant Breeding and Genetics, College of Agriculture, University of Sargodha, Sargodha, 40100, Pakistan \\ *For correspondence: imran.hamid@uos.edu.pk \\ Received 10 December 2020; Accepted 03 February 2021; Published 10 July 2021
}

\begin{abstract}
The aim of this study was to screen the potential of locally grown sugarcane genotypes for red rot resistance and activity of native microbial strains against the pathogen. Field trials were conducted with 70 genotypes for consecutive years and results showed that only two genotypes viz., SSRI-1 and CO-0238 showed resistant behavior towards red rot of sugarcane. The red rot pathogen Colletotrichum falcatum Went was characterized and pathogenicity tests on two susceptible genotypes (NSG-59 and CPSG-2923) showed high virulence of SUCF04 isolate to develop severe disease lesions. The native rhizospheric microbiota was screened for microbial consortia exhibiting fine antifungal activity against the highly virulent pathogenic strain. The antagonism assay exposed that 10 bacterial isolates out of 46 showed great potential for antifungal activity. The selected bacterial isolates revealed 68-99\% pathogen inhibition during the assay. The fungal strains with biological control potential inhibited the pathogen growth by $20-80 \%$ and a group of three strains with more than $50 \%$ antifungal activity were characterized. The molecular characterization of these microbes revealed that the isolates were belonging to Bacillus subtilus, Pseudomonas putida, Pseudomonas fluorescence, Trichoderma harzianum and several other important taxa. This study revealed that only two sugarcane genotypes were found as resistant against red rot pathogen, while most of the genotypes showed susceptible to moderately susceptible response. Moreover, the native residential microbiota associated with sugarcane exhibited great antifungal potential and can be utilized for disease protection and improved crop productivity. (C) 2021 Friends Science Publishers
\end{abstract}

Keywords: Antifungal activity; Disease severity; Red rot; Rhizospheric microbiota; Sugarcane

\section{Introduction}

Red rot of sugarcane (Sacchrum officinarium L.), caused by Colletotrichum falcatum Went, is the most devastating disease in sugarcane growing areas of the world and Pakistan as well and it is causing huge losses during production. It is responsible for the elimination of many productive varieties of sugarcane. Red rot is transmitted by soil and propagating materials, and due to the adverse losses, it is also called cancer of sugarcane (Kumar et al. 2010). The red rot disease minimizes the carbohydrates concentration in infected canes and severely affects the susceptible varieties (Agnihotri 1990). Moreover, the pathogen converts the sucrose into the glucose and fructose by the production of abundant quantity of enzyme invertases. Higher quantity of acid invertases in the highly susceptible varieties was recorded upon pathogen attack in susceptible as compared to resistant varieties (Silva and Bressiani 2005). The pathogen is responsible to reduce the cane weight up to $29 \%$ and also loss in sugarcane recovery was recorded up to $31 \%$ (Hassan et al. 2010). The pathogen colony was observed as dark grey with velvety surface on some sugarcane varieties and white to light ashy grey with cottony surface on others (Prittesh et al. 2016; Raza et al. 2019). Due to cultivation of susceptible varieties over years, many new pathovars have been evolved and many commercial varieties like CoL-54, Triton and BF-162 have been eliminated from Pakistan (Khan et al. 2011).

Sugarcane is a significant cash crop cultivated in tropical and sub-tropical areas of the world. It is precious crop due to its storing ability of high concentrations of sucrose or sugar in the stem and nowadays it is also used for biofuel resources for the manufacturing of ethanol (Menossi et al. 2008; Costa et al. 2011). It is valued at approximately US $\$ 143$ billion per year in the world. Globally, about $75 \%$ of the world sucrose production comes from sugarcane (Silva and Bressiani 2005; Prathima et al. 2013). India is on $1^{\text {st }}$ number in the production of sugarcane with 33.07

To cite this paper: Aslam S, MI Hamid, MU Ghazanfar, N Akhtar (2021). Assessment of sugarcane genotypes for red rot resistance and antifungal activity of rhizosphere microbiota against Colletotricum falcatum. Intl J Agric Biol 26:241-250 
million metric tons of the world sugar production followed by Brazil, EU, Thailand, China, United States, Mexico, Pakistan, Australia and Guatemala (FAO 2020). Sugarcane crop is cultivated on 1313 thousand hectares in Pakistan from which Punjab province shares $62 \%$, Sindh $26 \%$ and KPK shares $16 \%$ of the total area with annual production of 81.102 million tons (GOP 2018).

Management practice through fungicides is not so attractive and effective due to nature of pathogen and health hazard effects on humans and environment (Hassan et al. 2010; Mwaheb et al. 2017). Use of red rot resistant varieties through breeding program is more suitable practice to manage this disease (Sengar et al. 2009). Furthermore, biological control with rhizobacteria offers a simple and cost-effective strategy for managing soil-borne pathogens. Induction of plant resistance and antibiosis are the most common mechanisms adopted by bacteria with biocontrol potential (Gamalero et al. 2009; Topalović et al. 2020). In recent years, certain rhizospheric bacterial strains belonging to Pseudomonas, Bacillus, Rhizobium have drawn the attention of researchers due to their promising pathogen suppression ability (Tewari and Arora 2016; Kotasthane et al. 2017; Hussain et al. 2018; Shoaib et al. 2020; Sharf et al. 2021). The fungal biocontrol strains also provide promising disease control by direct mycoparasitism and producing antifungal compounds (Khan and Javaid 2020). The best studied Trichoderma spp. are known to be endophytic plant opportunistic symbionts as well as Trichoderma interaction with plants known to induce transcriptomic changes in relation to defense mechanism in plants, and some are known to protect plants from diseases and abiotic stresses (Bae et al. 2009; Ali et al. 2020). Trichoderma spp. isolated from plant rhizosphere have promising effect to showing antifungal activity against red rot of sugarcane during both in vitro and in vivo conditions (Viswanathan and Malathi 2019). Moreover, the beneficial microbes residing in plant rhizosphere may play multiple roles in plant production and protection.

This study was designed to collect the commercially grown sugarcane genotypes from different research institutes and sugarcane industry for screening against red rot resistance under completely managed fields. Furthermore, collection of native rhizospheric bacterial and fungal strains with significant antifungal activity against red rot pathogen was the aim of this study.

\section{Materials and Methods}

\section{Collection of sugarcane genotypes for field trials}

Seventy sugarcane genotypes were collected from sugarcane research institute, Ayub Agriculture Research Institute (AARI) and sugarcane industry (Shakrganj Sugar Mills) during 2017. Field trials were conducted at research area of College of Agriculture, University of Sargodha, Pakistan. Sugarcane genotypes were sown in September
2017 and 2018 consecutively for two years. All the recommended cultural and agronomic practices were applied to field experiments in both the years. Natural disease incidence and disease severity were scored after ten months of sowing. Disease incidence was calculated as described by Hassan et al. (2011) and disease severity was calculated according to the scale given by Kalaimani (2000).

\section{Pathogenicity on sugarcane}

The red rot pathogen was isolated from diseased samples collected from sugarcane field sown for screening of genotypes. The pathogen was isolated from infected cane and leaf lesions on potato dextrose agar medium. The pathogen was purified and morphologically identified as described by Sharma et al. (2005). The pathogenic isolates were molecularly characterized by the DNA extraction by using 2\% CTAB method as described by Sambrook and Russel (2001). The PCR analysis was performed by using the extracted DNA (20-50 ng) from the mycelium by using the ITS1: 5'TCCGTAGGTGAACCTGCGG3' and ITS4: 5'TCCTCCGCTTATTGATATGC3' primer pair. The sequences were analyzed by using Blast tools in NCBI database and NJ tree was constructed by MEGA 6.0 (Tamura et al. 2013). Two susceptible genotypes of sugarcane were selected for pathogenicity assays on the basis of disease severity data. The pathogenicity assays were conducted by using detached health leaves and sets of sugarcane. A mycelial plug of $5 \mathrm{~mm}$ from 7 days old cultures of pathogen were collected and placed on surface sterilized leaves by puncturing the midrib. The sugarcane sets were inoculated with $5 \mathrm{~mm}$ agar plug by making a hole with borer. The holes were closed with cotton plug and wrapped with thin plastic sheet. The inoculated leaves and sets were incubated in moist chambers at $25^{\circ} \mathrm{C}$. The data for lesion development was recorded at 7 days per inoculation. The pathogenicity assays were repeated twice with same conditions.

\section{Isolation of rhizospheric microbiota}

The rhizosphere soil was collected from the sugarcane asymptomatic plants in the vicinity of symptomatic plants by carefully collecting the roots. The bulk soil was removed and rhizosphere soil was collected by washing the roots with sterilized distilled water followed by $10 \mathrm{~min}$ centrifugation at 10,000 rpm (Hamid et al. 2017). For bacterial isolations, serial dilutions were prepared and 200 $\mu \mathrm{L}$ suspensions were spread on nutrient agar and King's B media. The bacterial colonies were observed on daily basis and forty-six clones were picked randomly on the basis of colony morphology for further purification. The purified cultures were stored at $-20^{\circ} \mathrm{C}$ for fungal isolations, $3^{\text {rd }}$ dilution of rhizosphere soil was placed on freshly prepared PDA plates and incubated at $25^{\circ} \mathrm{C}$ for $2-3$ days. The plates were observed and emerging fungal colonies were picked 
and transferred to freshly prepared PDA plates and individual cultures of each isolate was developed for further assays. The fungal colonies were observed morphologically and thirteen fungal isolates were selected on the basis of morphological characters for further antagonistic assays.

\section{In vitro antagonistic assays with bacterial strains}

The isolated bacteria were screened for their antagonistic activity against aggressive isolate of red rot causing pathogen $C$. falcatum. In vitro antagonistic activity was monitored by dual culture assay by following the Hassan et al. (2010). Briefly, bacterial cultures from all selected isolates were streaked in the middle of the Petri plate containing PDA medium. The mycelial agar plug of $5 \mathrm{~mm}$ from 5 days old colony was placed with equidistance side of plate. The plates with negative controls contained only the pathogen culture. The plates were incubated at $25 \pm 2^{\circ} \mathrm{C}$ and the assay was conducted with three replicates for each isolate. The plates were observed on daily basis and scoring for the activity of antagonistic bacteria was recorded at 72 $96 \mathrm{~h}$ (Perneel et al. 2007). The fungal hyphae overgrown by bacterial culture were scored as zero, hyphae at the edge of the bacterial culture were scored as 1 and bacterial isolates showed distinct inhibition zone were scored as 2 . The bacterial isolates scored as 2 were selected for further assays on the basis of the antagonistic potential. The selected isolates were molecularly characterized by using $16 \mathrm{~S}$ rRNA gene primers and sequences were analyzed and submitted in the NCBI database. The multiple alignments were developed by ClustalX and maximum likelihood tree was generated with the WAG Model in MEGA 6.0 using 1,000 bootstrap values.

\section{Round circle antagonistic assay}

The round circle assay was conducted to test the potential of selected bacterial isolates against red rot pathogen by following the Hassan et al. (2010). The mycelial agar disc of $10 \mathrm{~mm}$ was placed in the center of Petri plate containing PDA medium. A circular line, made with a $6-\mathrm{cm}$ diameter Petri dish dipped in a suspension of antagonistic bacteria $\left(5 \times 10^{9} \mathrm{cfu} \mathrm{mL}^{-1}\right)$, was placed surrounding the fungal mycelial agar disc. The plates with all bacterial isolates were incubated at $25^{\circ} \mathrm{C}$ for $72 \mathrm{~h}$. The assay was conducted with three replicates and repeated twice. The data for fungal pathogen growth was measured and compared with the control plates having only pathogen culture. The fungal inhibition by bacterial isolates was calculated by using the formula:

$$
\% \text { inhibition }=[1-(\text { Fungal growth/Control growth })] \times 100
$$

\section{Agar disc diffusion method}

The selected bacterial isolates were further screened for antagonistic potential against red rot pathogen by using agar disc diffusion method. The mycelium of pathogenic fungus was grounded in mortar and pestle with sterilized distilled water and $100 \mu \mathrm{L}$ mycelial suspensions was inoculated on PDA medium. The bacterial culture loops $\left(5 \times 10^{9} \mathrm{cfu} \mathrm{mL}^{-1}\right)$ were placed at four equidistance points in the Petri plates. The assay was conducted with three replicates. The plates were incubated at $25^{\circ} \mathrm{C}$ for $72 \mathrm{~h}$. The data for the inhibition of fungal growth was recorded by following the Balouiri et al. (2016). The antagonistic assays were repeated twice with same conditions.

\section{Antagonistic assays with fungi}

The selected fungal isolates were screened for their antagonistic activity against pathogen of red rot of sugarcane. In vitro antifungal activity was evaluated by dual culture assays. Fungal mycelium plug of $5 \mathrm{~mm}$ was placed equal distance from pathogen mycelial plug in PDA containing plates. The control plates contained only the pathogen culture. The plates were incubated at $25 \pm 2^{\circ} \mathrm{C}$ and the assay was conducted with three replicates for each fungal isolate. The plates were observed on daily basis and scoring for the activity of antagonistic fungal isolates was recorded after 7 days of incubation by the formula given by Hajieghrari et al. (2008).

$$
\% \text { inhibition }=(C-T) \times 100 / C
$$

\section{Data analysis}

The statistical analyses were independently conducted for all experiments. The variance analysis was obtained by using SAS software by SAS Institute to compare the mean values.

\section{Results}

\section{Response of sugarcane genotypes for red rot resistance}

The sugarcane genotypes showed varied repose against red rot pathogen in both cultivation years. The results revealed that during the field trial of 2018, 19 genotypes showed susceptible response, 32 genotypes showed moderately susceptible response, 16 genotypes were moderately resistant response and only 3 genotypes (CP-368, SSRI-1, CO-0238) behaved as resistant against red rot disease. During the field trial of 2019, most of the genotypes showed almost similar response as compare to the 2018 trial against C. falcatum. During 2019 trial, genotypes changed some mode of reaction towards the pathogen severity from which 33 were moderately susceptible and 16 were moderately resistant in their behavior against red rot. Only two genotypes SSRI-1 and CO-0238 were found resistant during both years. In 2019, two susceptible genotypes CPF-237 and CPS-437 showed better response and fall in category of moderately susceptible. Two moderately resistant genotypes MSG-502 and CPSG-2730 changed the response to moderately susceptible. The genotypes US-658 and 

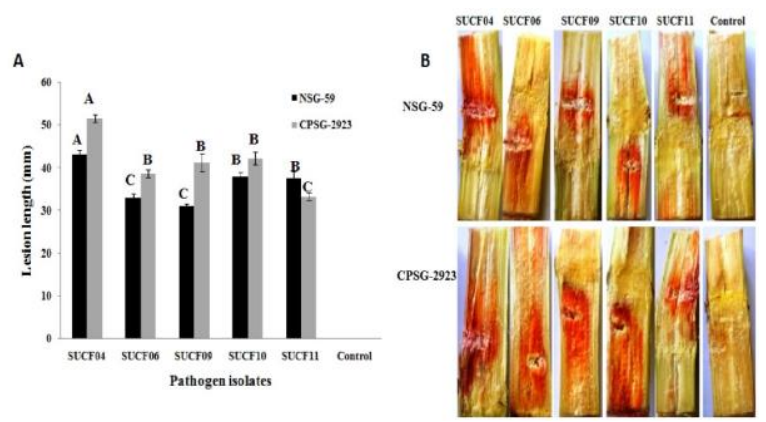

Fig. 1: The pathogenicity of Colletotricum falcatum isolates on sugarcane sets of two susceptible genotypes. (A) The data indicates the aggressiveness of red rot isolates on sugarcane sets (B) Sugarcane sets with red rot lesions developed in 7 dpi

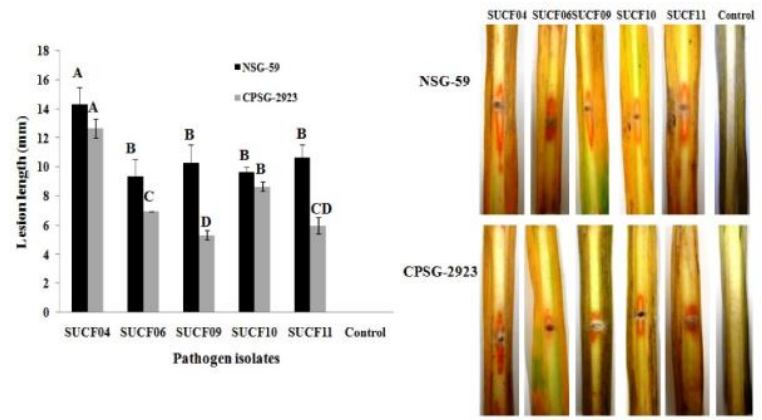

Fig. 2: The pathogenicity of Colletotricum falcatum isolates on sugarcane detached leaves of two susceptible genotypes. (A) The data presents the aggressiveness of red rot isolates on sugarcane detached leaves (B) Sugarcane leaves with red rot lesions developed in $7 \mathrm{dpi}$

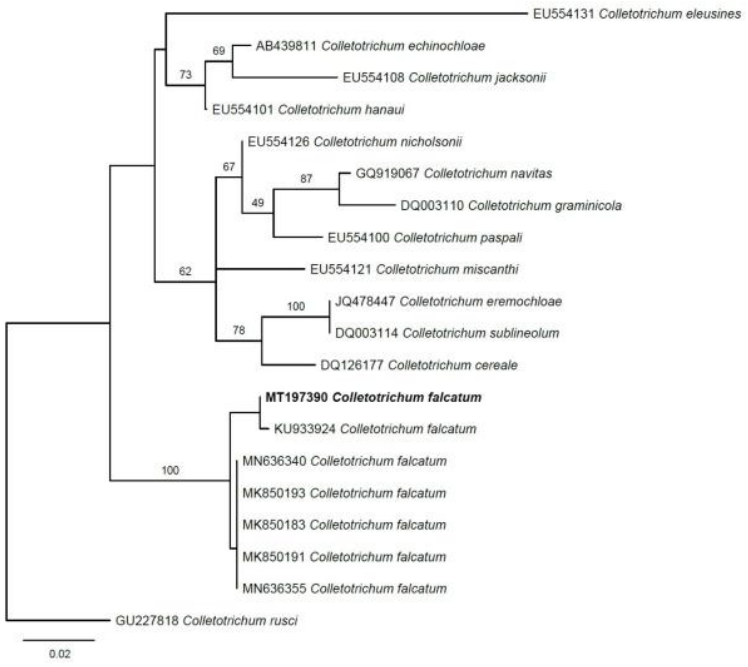

Fig. 3: Phylogenetics tree of nucleotide sequences of SUCF04 isolate of Colletotricum falcatum constructed using MEGA6.0 program (Tamura et al. 2013). The evolutionary history was inferred using the Maximum likelihood method with 1000 bootstrap values

CPSG-2415 changed into susceptible from moderator susceptible during the years 2019. One of the resistant genotype CP-368 converted to moderately resistant. Highly susceptible line was not found during the trials in this semiarid region. Two susceptible genotypes NSG-59 and CPSG2923 showed the same behavior towards pathogen in both year trials (Table 1). Therefore, these two genotypes were selected for further experiments. The data for red rot disease incidence and severity revealed that pathogen is prevalent in this area and only resistant to moderately resistant genotypes should be selected for cultivation.

\section{In vitro response of red rot pathogen on susceptible genotypes}

The red rot pathogen was isolated from the diseased plants collected from sugarcane field. A total of 31 pathogenic isolates were purified on potato dextrose agar and characterized morphologically. The morphological characters of 13 isolates were similar to Colletotricum falcatum. On the basis of colony growth and color, 5 isolates were selected for further pathogenicity assays (Table 2) on two susceptible genotypes of sugarcane (NSG59, CPSG-2923). The in vitro pathogenicity assays were performed on sugarcane sets and detached leaves. The selected isolates showed different response on two genotypes by the formation of red rot lesions in both assays. The isolates also showed different disease aggressiveness on two genotypes. The isolated SUCF04 showed more aggressive response on both sugarcane genotypes as compare to the other isolates and control (Fig. 1). During the pathogenicity on sugarcane sets, all the isolates showed high disease development on CPSG-2923 genotype while in detached leaf assay, all isolates showed more disease pattern on NSG-59 genotype (Fig. 2). On the basis of disease aggressive patterns, SUCF04 isolate was characterized through DNA sequencing of ITS locus (accession number MT197390) and phylogenetics analysis revealed close resemblance with $C$. falcatum (Fig. 3). The result showed that isolates of red rot pathogen developed the disease on sugarcane sets and detached leaves under controlled conditions and showed differential disease aggressiveness. The assays were repeated twice under same conditions.

\section{Antagonistic activity of bacterial isolates against red rot pathogen}

The rhizosphere soil was collected from healthy sugarcane plants and prepared for the isolation of bacteria. The morphological different isolates were picked and forty-six purified cultures were developed. The selected bacterial isolates were screened for antagonistic activity against red rot pathogen in dual culture assay. The result showed that 17 bacterial isolates out of 46 were able to inhibit the growth of C. falcatum ranging from $58-97 \%$. While considered the antagonistic activity rating of bacterial isolates to inhibit the pathogen growth as described in (Table 3), only 10 bacterial isolates were able to form distinct inhibition zones with 
Assessment of Sugarcane Genotypes for Red Rot Resistance / Intl J Agric Biol, Vol 26, No 2, 2021

Table 1: Monitoring the disease incidence and response to pathogen on different sugarcane genotypes during the field trials of 2018 and 2019

\begin{tabular}{|c|c|c|c|c|c|c|c|c|c|c|c|}
\hline Sr No. & Cultivar & \% DI 2018 & RP 2018 & \% DI 2019 & RP 2019 & Sr No. & Cultivar & \% DI 2018 & RP 2018 & \% DI 2019 & RP 2019 \\
\hline 1 & SPF- 213 & 31.67 & MR & 35.11 & MR & 36 & CPSG- 2730 & 46.67 & $\mathrm{MS}$ & 48.11 & MS \\
\hline 2 & SPF- 220 & 25.67 & MR & 25.17 & MR & 37 & YT- 910 & 51.33 & MS & 55.55 & MS \\
\hline 3 & SPF- 234 & 27.67 & MR & 24.61 & MR & 38 & SPSG- 24 & 42.67 & MS & 45.88 & MS \\
\hline 5 & HSF- 240 & 34 & MR & 38 & MR & 40 & SPSG- 27 & 38.33 & MR & 39 & MR \\
\hline 6 & CP- $67-500$ & 54.33 & MS & 55.12 & MS & 41 & SPSG- 26 & 52.67 & MS & 51.11 & MS \\
\hline 7 & SPF- 2038 & 49.33 & MS & 45.78 & MS & 42 & SSRI- 4 & 48.33 & MS & 55 & MS \\
\hline 8 & CO- 1148 & 64.33 & $\mathrm{~S}$ & 76.43 & S & 43 & SPSG- 25 & 36.33 & MR & 38.80 & MR \\
\hline 9 & NSG- 59 & 78 & $\mathrm{~S}$ & 80 & $\mathrm{~S}$ & 44 & SSRI- 1 & 9.33 & $\mathrm{R}$ & 12.45 & $\mathrm{R}$ \\
\hline 10 & CPSG-2923 & 76.33 & S & 77.90 & $S$ & 45 & SSRI- 7 & 41.67 & MS & 45.94 & MS \\
\hline 11 & YT- 55 & 62.67 & $\mathrm{~S}$ & 60 & S & 46 & SSRI- 6 & 69 & S & 84 & $\mathrm{~S}$ \\
\hline 12 & US- 658 & 55.67 & MS & 60 & $S$ & 47 & US- 718 & 73.67 & $\mathrm{~S}$ & 78.56 & $\mathrm{~S}$ \\
\hline 13 & US- 130 & 80.67 & S & 86.23 & S & 48 & SSRI- 3 & 36.33 & MR & 38.67 & MR \\
\hline 14 & US- 272 & 50 & MS & 52 & MS & 49 & SPSG- 29 & 44.67 & MS & 49 & MS \\
\hline 15 & CSSG- 676 & 65 & S & 70 & S & 50 & INDIA- 1 & 51.33 & MS & 50 & MS \\
\hline 16 & US- 384 & 51.67 & MS & 55 & MS & 51 & THATHA- 1312 & 23.67 & MR & 32 & MR \\
\hline 18 & US- 133 & 74.33 & S & 80 & $\mathrm{~S}$ & 53 & MSG- 502 & 39 & MR & 41 & MS \\
\hline 19 & CPS- 437 & 63 & $\mathrm{~S}$ & 59 & MS & 54 & CPSG- 2730 & 54.33 & MR & 59 & MS \\
\hline 20 & US- 127 & 48.33 & MS & 45 & MS & 55 & AUST- 134 & 37.67 & MR & 39 & MR \\
\hline 21 & CPF- 247 & 61.33 & S & 64.12 & S & 56 & NIFA- 01 & 46 & MS & 55 & MS \\
\hline 22 & CPF- 246 & 52.33 & MS & 48 & MS & 57 & CSSG- 33 & 44 & MS & 45 & MS \\
\hline 23 & HOSG- 315 & 54.67 & MS & 59.45 & MS & 58 & US- 832 & 48 & MS & 51.92 & MS \\
\hline 24 & CPF- 248 & 74.67 & $\mathrm{~S}$ & 77.11 & S & 59 & CSSG- 23 & 42.33 & MS & 45.55 & MS \\
\hline 25 & US- 633 & 74 & $\mathrm{~S}$ & 75.67 & $\mathrm{~S}$ & 60 & CSSG- 32 & 37.67 & MR & 39.11 & MR \\
\hline 26 & XT- 236 & 47.67 & MS & 48.81 & MS & 61 & SPSG- 27 & 42.67 & MS & 45.53 & MS \\
\hline 27 & CSSG- 2402 & 65.33 & S & 61.33 & S & 62 & US- 272 & 71.67 & S & 73.21 & S \\
\hline 28 & CPSG- 2525 & 71.33 & $\mathrm{~S}$ & 72.56 & $\mathrm{~S}$ & 63 & YT- 53 & 45.67 & MS & 49.99 & MS \\
\hline 29 & FST- 19 & 41.67 & MS & 38 & MR & 64 & CSSG- 25 & 49.33 & MS & 50 & MS \\
\hline 30 & CPSG- 2415 & 59 & MS & 62 & S & 65 & US- 204 & 31 & MR & 25 & MR \\
\hline 31 & CP- 368 & 17.33 & $\mathrm{R}$ & 23.45 & MR & 66 & YT- 910 & 30 & MR & 32 & MR \\
\hline 32 & CPSG- 2718 & 45 & MS & 54.44 & MS & 67 & CPSG- 2500 & 52.67 & MS & 55.15 & MS \\
\hline 33 & CPSG- 3481 & 35.67 & MR & 39.35 & MR & 68 & SSRI- 2 & 32 & MR & 34.72 & MR \\
\hline
\end{tabular}

DI: Disease Incidence, RP: Response to Pathogen

Table 2: The morphological characters of the isolates of red rot pathogen

\begin{tabular}{llll}
\hline Sr No. & Isolates & Mycelial growth $(\mathrm{cm})$ & Color \\
\hline 01 & SUCF04 & $8.56 \pm 0.208$ & White to light grey \\
02 & SUCF06 & $8.73 \pm 0.208$ & Whitish grey \\
03 & SUCF09 & $7.33 \pm 0.152$ & Dull white \\
04 & SUCF10 & $8.9 \pm 0.1$ & White \\
05 & SUCF11 & $7.9 \pm 0.152$ & Light grey \\
\hline
\end{tabular}

pathogen which were scored as 2. Moreover, 7 bacterial isolates limited the growth of pathogen without making distinct inhibition zones were rated as 1 . All other bacterial isolates showed no antagonistic activities were rated as 0 . The bacterial isolates showed the antagonistic score as 2 were further characterized by using 16SrRNA gene and accession numbers are provided (Table 4). These selected 10 bacterial isolates showed high antagonistic activity by the inhibition of fungal growth from 71-96\% (Table 3). The result revealed that potential bacterial isolates were resided in the rhizosphere of healthy sugarcane to protect against red rot pathogen.

\section{Confirmation of antagonistic activity of selected bacterial strains}

Bacterial strains with maximum antagonistic activity (score
2) were further evaluated to confirm the inhibition of $C$. falcatum mycelial growth by round circle assay. The pathogen and bacterial isolates were inoculated and the mycelcial growth inhibition was measured. The result showed that bacterial strains inhibited the growth of pathogen by $68-99 \%$ during the assay. The bacterial strain BA18 showed maximum inhibition of pathogen growth (99\%) followed by BA19 with the inhibition of $96 \%$. The bacterial strain BA34 inhibited the pathogen growth by $(95 \%)$ followed by BA33 (94\%), BA39 (92\%) and BA44 $(90 \%)$ respectively. The minimum growth inhibition was observed by the bacterial strain BA32 which was $68 \%$ in this assay (Fig. 4A). The result demonstrated the best antagonistic activity of bacterial strains during the round circle assay by inhibiting the pathogen growth. The selected bacterial strains were further confirmed for antagonistic activity by agar disc diffusion method. In this assay, 
Aslam et al. / Intl J Agric Biol, Vol 26, No 2, 2021

Table 3: The bacterial isolates collected from sugarcane rhizosphere and antagonistic activity against Colletotricum falcatum

\begin{tabular}{llllll}
\hline Bacterial Isolates & Antagonistic activity & Pathogen inhibition $\%$ & Bacterial Isolates & Antagonistic activity & Pathogen inhibition \% \\
\hline BA1 & 0 & 0 & BA24 & 0 & 0 \\
BA2 & 0 & 0 & BA25 & 0 & 0 \\
BA3 & 0 & 0 & BA26 & 0 & 0 \\
BA4 & 0 & 0 & BA27 & 0 & 0 \\
BA5 & 0 & 0 & BA28 & 0 & 0 \\
BA6 & 0 & 0 & BA29 & 0 & 0 \\
BA7 & 0 & 0 & BA30 & 0 & 0 \\
BA8 & 0 & 0 & BA31 & 0 & $97 \%$ \\
BA9 & 0 & 0 & BA32 & 2 & $90 \%$ \\
BA10 & 1 & $79 \%$ & BA33 & 2 & $60 \%$ \\
BA11 & 0 & 0 & BA34 & 1 & $58 \%$ \\
BA12 & 0 & 0 & BA35 & 1 & $71 \%$ \\
BA13 & 0 & 0 & BA36 & 1 & $96 \%$ \\
BA14 & 0 & 0 & BA37 & 2 & 0 \\
BA15 & 0 & 0 & BA38 & 2 & 0 \\
BA16 & 0 & 0 & BA40 & 2 & $60 \%$ \\
BA17 & 1 & $80 \%$ & BA41 & 0 & $61 \%$ \\
BA18 & 2 & $97 \%$ & BA42 & 1 & $92 \%$ \\
BA19 & 2 & $92 \%$ & BA43 & 1 & $0 \%$ \\
BA20 & 2 & $76 \%$ & BA44 & 2 & $0 \%$ \\
BA21 & 2 & $78 \%$ & BA46 & 0 & 0 \\
BA22 & 0 & 0 & & 0 \\
BA23 & 0 & 0 & & & \\
\hline
\end{tabular}

Table 4: The characterization of microbial strains isolated from the rhizosphere of healthy sugarcane plants with the antifungal activity against red rot pathogen

\begin{tabular}{llll}
\hline Sr No & Isolates & Microbial Strain & Accession No \\
\hline 1 & BA10 & Oceanobacillus kimchi & MT380165 \\
2 & BA17 & Duganella zoogloeoides & MT380163 \\
3 & BA18 & Bacillus subtilus & MT197386 \\
4 & BA19 & Pseudomonas putida & MT197387 \\
5 & BA21 & Pseudomonas geniculate & MT197383 \\
6 & BA32 & Acinoetobacter calcoacetius & MT197389 \\
7 & BA33 & Pseudomonas putida & MT197385 \\
8 & BA34 & Pseudomonas fluorescence & MT197384 \\
9 & BA39 & Rhizobium pusense & MT197388 \\
10 & BA44 & Bacillus licheniformis & MT380164 \\
11 & FU12 & Phoma harbarum & MT974244 \\
12 & FU15 & Conithyrium aleuritis & MT974245 \\
13 & FU19 & Trichoderma harzianum & MT974243 \\
\hline
\end{tabular}

formation of clear inhibition zones by bacterial strains were measured and the data revealed that all selected bacterial strains formed clear inhibition zones by limiting the growth of pathogen. The range of inhibition zones formed by bacterial strains was $4.5-15.6 \mathrm{~mm}$ while comparing with control with no inhibition zone. The bacterial strain BA33 formed maximum inhibition zone of $15.6 \mathrm{~mm}$ followed by BA34 with $13.33 \mathrm{~mm}$ zone. Moreover, bacterial strain BA19 formed $10.4 \mathrm{~mm}$ inhibition zone and minimum zone was formed by BA21 $(4.5 \mathrm{~mm})$ during the assay (Fig. 4B). The bacterial strains proved to have high antagonistic ability against the red rot pathogen of sugarcane. Furthermore, these bacterial strains will be screened for the antagonistic activity during green house and field trials in future studies, the range of zone inhibition diameter was $(4.5-15.6 \mathrm{~mm})$ as compare to control in which zone inhibition diameter was 0 . The bacterial strain BA33 showed maximum diameter of zone inhibition $(15.6 \mathrm{~mm})$ followed by BA34 $(13.33 \mathrm{~mm})$,
BA19 $(10.4 \mathrm{~mm})$, BA39 $(8.7 \mathrm{~mm})$, BA18 $(7.3 \mathrm{~mm})$ and BA44 $(6.8 \mathrm{~mm})$. Minimum zone inhibition was showed by isolate BA21 $(4.5 \mathrm{~mm})$. The control plates were observed with full growth of pathogenic fungus (Fig. 4B). The antagonistic assays were repeated twice with similar conditions. The ten selected bacterial isolates were characterized and phylogenetics analysis showed that native strains have close match with the strains from other regions of world (Fig. 5). The results revealed that resident microbiota have potential to suppress the red rot causing pathogen. These selected bacterial strains will be further evaluated in green house and field trials.

\section{Antagonistic activity of fungal isolates against $C$. falcatum}

The antagonistic activity of selected fungal isolates was carried out in dual culture assay. A total of 35 fungal isolates were selected on the basis of morphology for in vitro dual culture assay. The result revealed that thirteen fungal isolates were capable to suppress the mycelial growth of $C$. falcatum with varying degree of antagonism. The results showed that fungal isolates were capable to inhibit the mycelial growth of pathogen ranging from 21-81\% during dual assay (Fig. 6). While considered the antagonistic activity rating of fungal isolates to inhibit the pathogen growth, only three fungal isolates showed more than 50\% antagonistic activity against pathogen. Furthermore, isolate FU19 showed mycelial inhibition of pathogen to $81 \%$ while isolate FU12 and FU15 showed inhibition up to $72 \%$ and $58 \%$ respectively (Fig. 6). These three isolates were further molecularly characterized by using ITS1 and ITS4 primers and accession numbers are provided (Table 3). The results described that fungal taxa 
A
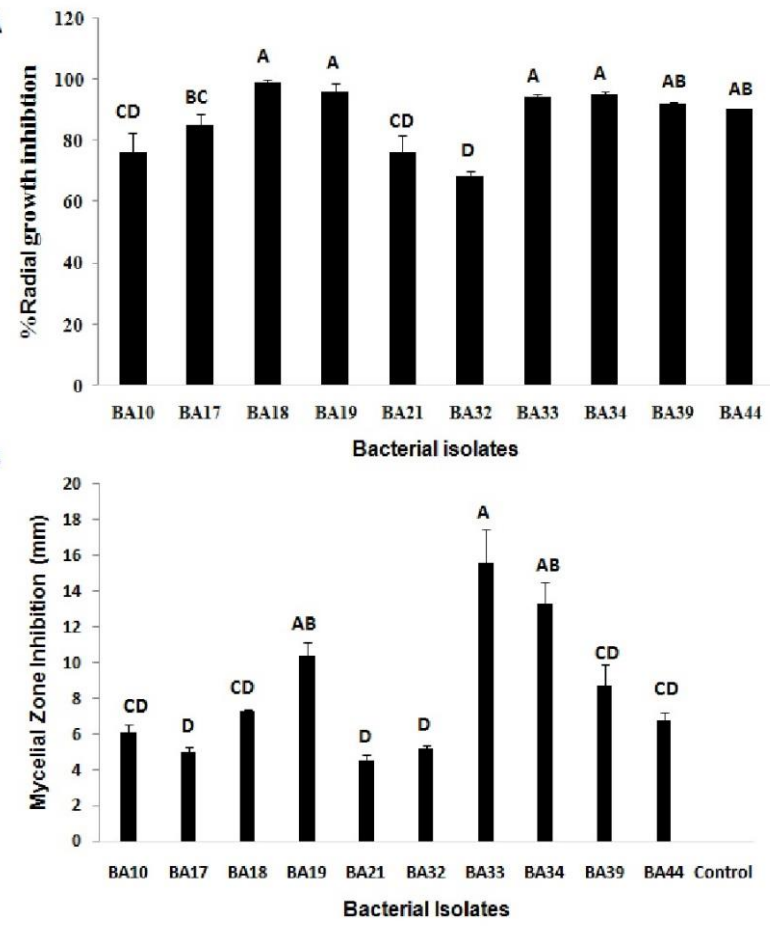

Fig. 4: The inhibition of radial growth of $C$. falcatum in circular plate assay. (A)- Percentage inhibition of radial growth of pathogenic fungus by selected bacterial strains. (B)- Mycelial inhibition zones measurements by the inoculation of selected bacterial strains

residing in the rhizosphere of healthy sugarcane plants have potential to protect the plants from red rot pathogen.

\section{Discussion}

The red rot disease is the main constraint in the production of sugarcane and resistant varieties changed the behavior to susceptible towards pathogen with passage of time. It is the need of time to develop new resistant cultivars of sugarcane against red rot pathogen. This study was conducted to screen the potential of locally available sugarcane genotypes against red rot disease under field conditions. The results showed that only 3 genotypes behaved as resistant against C. falcatum during trial year 2018 and only 2 genotypes were resistant during year 2019. All other cultivars studied during the 2 years field trials exhibited moderately resistant to susceptible response. Moreover, breeding programs for red rot resistance was implemented in sugarcane and several advanced lines showed resistance to $C$. falcatum and several resistance genes have been identified in sugarcane that may confer resistance through breeding programs (Hameed et al. 2015). Moreover, several highly productive and resistant sugarcane varieties such as CoL-54, Triton and BF-162 were banned in past due to the increased susceptibility towards $C$. falcatum (Khan et al. 2011). The alteration in resistance response is possibly due the alternations in the

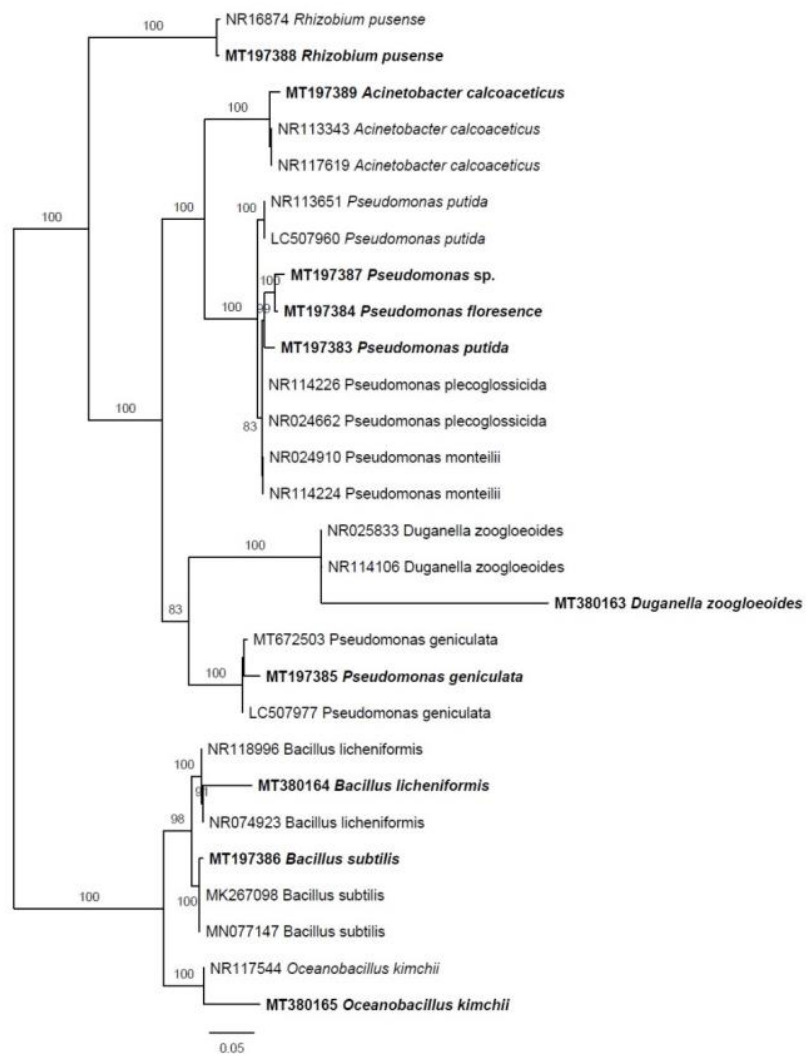

Fig. 5: Phylogenetics tree of nucleotide sequences of 10 selected bacterial strains from rhizosphere of sugarcane constructed using MEGA6.0 program (Tamura et al. 2013). The evolutionary history was inferred using the Maximum Likelihood method with 1000 bootstrap values

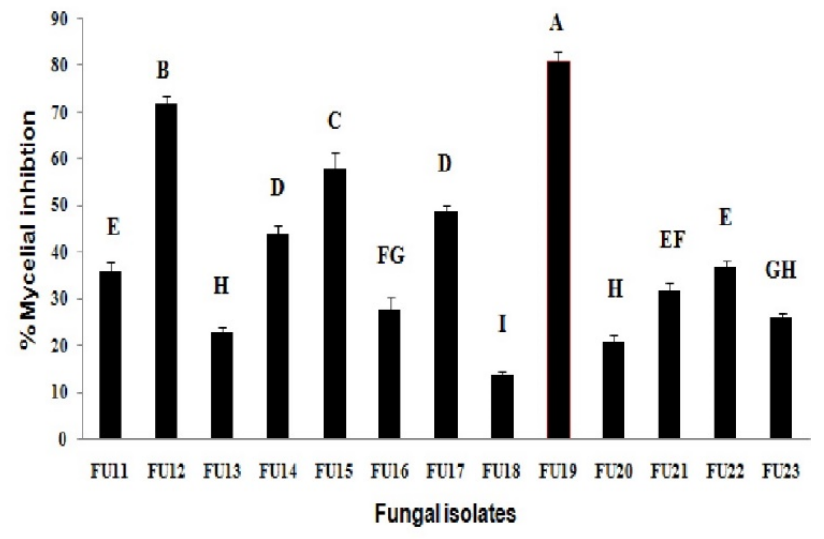

Fig. 6: In vitro suppression of $C$. falcatum by the selected fungal strains during the dual culture assay

pathogenic strains of $C$. falcatum by which virulence of pathogen varied from region to region and also with passage of time (Viswanathan et al. 2003). C. falcatum was grouped in to a set of 14 host differentials, and so far, revealed the presence of 11 pathotypes (CF01-CF-11) from various tropical and subtropical regions (Viswanathan 2010). 
This phenomenon revealed the change in the virulence of pathogen and varietal reactions to pathogen over time.

Soil microbes are diverse and play several functional services for the plant including nutrient acquisition, growth promotion and disease suppression (Wang et al. 2016a, b; Wu et al. 2019a, b; Bai et al. 2020; Hu et al. 2020). The selection of effective antagonistic strains from the plant rhizosphere supported the approach of isolation of biocontrol agents from the target crop and same environment where they will be used commercially (Landa et al. 1997). Biological based plant resistance induction can provide new ways to manage this deleterious disease of sugarcane (Hassan et al. 2011). Antagonistic bacterial based resistance induction is cost effective and simple strategy. Rhizospheric microbes played essential roles in pathogen suppression by following different mechanisms (Hassan et al. 2010; Hussain et al. 2016; Zhang et al. 2019; Khan et al. 2021). This study was designed to characterize and evaluate the effective antagonistic bacterial isolates collected from the rhizosphere of healthy sugarcane plants. The results of pathogenicity test showed that $C$. falcatum isolated from diseased plants of sugarcane have different level of virulence to susceptible genotypes. The previous study also revealed during in vitro pathogenicity assays that $C$. falcatum isolates from the region keep varied degree of virulence (Hassan et al. 2010). Potential biocontrol agents were obtained by isolating the bacteria and fungi from sugarcane rhizosphere and detecting the in vitro antagonistic activity against the pathogen. The native antagonistic microbiota was screened for antifungal activity and 10 potential bacterial and 13 fungal strains were further evaluated in different antagonistic assays.

The rhizobacterial strains inhibited the mycelial growth of $C$. falcatum up to 68-99\% in dual culture assays. The Bacillus subtilus strain BA18 showed maximum inhibition of fungal growth up to $99 \%$. It seems that inhibition of fungal pathogen growth by the production of diverse antibacterial and antifungal compounds, such as zwittermicin, kanosamine and lipopeptides for disease suppression. Iturins and fengycins display strong antifungal activities, and inhibit the growth of a wide range of plant pathogens (Kim et al. 2013; Guo et al. 2014). Pseudomonas putida strain BA19 and BA21 showed 96 and $76 \%$ disease suppression respectively, during in vitro assays. Sun et al. (2017) proved during in vitro experiment that Pseudomonas putida is an effective biocontrol agent against tomato bacterial wilt disease and many other soils borne diseases. Pyoluteorin, pyrrolnitrin, 2,4-diacetylphloroglucinol and phenazine are the major determinants of the biocontrol activity of pseudomonads (Haas and Defagoo 2005; Hassan et al. 2011; Bernal et al. 2017). Pang et al. (2016) revealed that Pseudomonas putida is responsible as promising biocontrol agent against stripe rust of wheat by increasing the yield. Isolated Pseudomonas flouresence BA34 showed distinct radial growth inhibition of $95 \%$ and $13.33 \mathrm{~mm}$ zone inhibition during antagonistic assays against red rot pathogen of sugarcane. It has been reported that Pseudomonas flouresence have great efficiency against sunflower diseases by the production of variety of metabolites including indole-3-acetic acid, siderophore, pyocyanin, hydrogen cyanide, chitinase, $\beta-1,3$ glucanase during both in vitro and in vivo conditions (Tewari and Arora 2016). It is documented that Pseudomonas flouresence is a potential bio-control agent against collar rot of chickpea by the formation of siderophore and cynogenic (Kotasthane et al. 2017). The Pseudomonas geniculata strain BA33 also has equal importance to suppress the $C$. falcatum up to $94 \%$ during screening of efficient bio control agent. This is consistent with reports in vitro and in vivo antagonistic activities of Pseudomonas geniculata against Verticillium wilt of cotton (Erdogan and Benlioglu 2010). The other bacterial strains also showed the distinct effect during antagonistic assays and proved that native residential microbiota might play important role in plant disease protection. The inhibition of $C$. falcatum by rhizospheric fungal isolates in dual culture assays was observed in this study. The selected fungal isolates showed varied degree of pathogen inhibition ranging from $58-81 \%$. During in vitro assays Trichoderma harzianum showed maximum antifungal activity by inhibiting the pathogen to $81 \%$. It has been reported that Trichoderma spp. showed promising effect against different plant pathogens (Bae et al. 2009; Viswanathan and Malathi 2019; Javaid et al. 2021). Isolate FU12 Phoma herbarum also behave effect antagonistic agent by showing $72 \%$ pathogen inhibition during in vitro assays. Phoma herbarum showed significant antagonistic activity against Colletotrichum gloeosporioides and therefore recommended as bio-control agent (Gupta et al. 2016). Biocontrol of C. falcatum was successfully accomplished by Pseudomonas strains and fungal agents during in vitro and field conditions (Joshi et al. 2016; Viswanathan and Malathi 2019). The other bacterial strains also showed the distinct effect during antagonistic assays and proved that native residential microbiota might play important role in plant disease protection.

\section{Conclusion}

The results of this study concluded that only few sugarcane genotypes are present in Pakistan that showed resistance to red rot pathogen under semi-arid climate. Moreover, targeted breeding programs need to be accomplished to develop disease resistance genotypes against red rot disease. The exploration of native microbiota with disease suppression potential can be promising alternatives while developing management strategies for sugarcane crop.

\section{Acknowledgments}

The authors are thankful to Sugarcane Research Institute Faisalabad, Shakarganj Sugar Mills and Ramzan Sugar Mills to provide sugarcane genotypes for trials. The funding 
for the research was provided by University of Sargodha under ORIC-UOS projects (UOS/ORIC/2016/14) and (UOS/ORIC/2016/16).

\section{Authors Contributions}

MIH and MUG planned the whole research work. SA and $\mathrm{MIH}$ conducted the research experimentation. MIH and NA collected the sugarcane genotypes. SA and MIH wrote the manuscript, MUG and NA reviewed the manuscript.

\section{Conflict of Interest}

The authors declare no conflicts of interest.

\section{Data Availability}

The data presented in the paper can be accessed in the public databases of NCBI.

\section{Ethics Approval}

No harm occurred to animals during this study.

\section{References}

Agnihotri VP (1990). Diseases of Sugarcane and Sugar Beet. Oxford and IBH, India

Ali A, A Javaid, A Shoaib, IH Khan (2020). Effect of soil amendment with Chenopodium album dry biomass and two Trichoderma species on growth of chickpea var. Noor 2009 in Sclerotium rolfsii contaminated soil. Egypt J Biol Pest Cont 30:102-110

Bae H, RC Sicher, MS Kim, SH Kim, MD Strem, RL Melnick, BA Bailey (2009). The beneficial endophyte Trichoderma hamatum isolate DIS $219 \mathrm{~b}$ promotes growth and delays the onset of the drought response in Theobroma cacao. J Exp Bot 60:3279-3295

Bai YC, YY Chang, M Hussain, B Lu, JP Zhang, XB Song, XS Lei, D Pei (2020). Soil chemical and microbiological properties are changed by long-term chemical fertilizers that limit ecosystem functioning. Microorganisms 8; Article 694

Balouiri M, M Sadiki, SK Ibnsouda (2016). Methods for in vitro evaluating antimicrobial activity: A review. J Pharm Anal 6:71-79

Bernal P, LP Allsopp, A Filloux, MA Llamas (2017). The Pseudomonas putida T6SS is a plant warden against phytopathogens. ISME $J$ 11:972-987

Costa MLM, LLB Amorim, AV Onofre, LJT de Melo, MBM de Oliveira, R de Carvalho, AM Benko-Iseppon (2011). Assessment of genetic diversity in contrasting sugarcane varieties using intersimple sequence repeat (ISSR) markers. Amer J Plant Sci 2:425-432

Erdogan O, K Benlioglu (2010). Biological control of Verticillium wilt on cotton by the use of fluorescent Pseudomonas spp. under field conditions. Biol Contr 53:39-45

FAO - Food and Agricultural Organization of United Nations (2020). Economic and Social Department: The Statistical Division, Rome, Italy

Gamalero E, G Lingua, G Berta, BR Glick (2009). Beneficial role of plant growth promoting bacteria and arbuscular mycorrhizal fungi on plant responses to heavy metal stress. Can J Microbiol 55:501-514

GOP (2018). Pakistan Economic Survey 2017-2018. Finance Division, Economic Advisor's Wing: Islamabad, Pakistan

Guo Q, W Dong, S Li, X Lu, P Wang, X Zhang, P Ma (2014). Fengycin produced by Bacillus subtilis NCD-2 plays a major role in biocontrol of cotton seedling damping-off disease. Microbiol Res 169:533-540
Gupta S, S Kaul, B Singh, RA Vishwakarma, MK Dhar (2016). Production of gentisyl alcohol from Phoma herbarum endophytic in Curcuma longa $\mathrm{L}$. and its antagonistic activity towards leaf spot pathogen Colletotrichum gloeosporioides. Appl Biochem Biotechnol 180:1093-1109

Haas D, G Défago (2005). Biological control of soil-borne pathogens by fluorescent pseudomonads. Nat Rev Microbiol 3:307-319

Hajieghrari B, M Torabi-Giglou, MR Mohammadi, M Davari (2008). Biological potential of some Iranian Trichoderma isolates in the control of soil borne plant pathogenic fungi. Afr J Biotechnol 7:967-972

Hameed U, YB Pan, J Iqbal (2015). Genetic analysis of resistance gene analogues from a sugarcane cultivar resistant to red rot disease. $J$ Phytopathol 163:755-763

Hamid MI, M Hussain, Y Wu, X Zhang, M Xiang, X Liu (2017). Successive soybean-monoculture cropping assembles rhizosphere microbial communities for the soil suppression of soybean cyst nematode. FEMS Microbiol Ecol 93; Article fiw222

Hassan MN, S Afghan, FY Hafeez (2011). Biological control of red rot in sugarcane by native pyoluteorin producing Pseudomonas putida strain NH50 under field conditions and its potential modes of action. Pest Manage Sci 67:1147-1154

Hassan MN, S Afghan, FY Hafeez (2010). Suppression of red rot caused by Colletotrichum falcatum on sugarcane plants using plant growthpromoting rhizobacteria. Biocontrol 55:531-542

Hu J, M Hussain, X Zhang, J Tian, X Liu, Y Duan, M Xiang (2020). Abundant and diverse fungal microbiota inhabit the white females and brown cysts of the cereal cyst nematode. Appl Soil Ecol 147:103372

Hussain M, MI Hamid, J Tian, J Hu, X Zhang, J Chen, M Xiang, X Liu (2018). Bacterial community assemblages in the rhizosphere soil, root endosphere and cyst of soybean cyst nematode-suppressive soil challenged with nematodes. FEMS Microbiol Ecol 94; Article fiy142

Hussain M, MI Hamid, N Wang, L Bin, M Xiang, X Liu (2016). The transcription factor SKN7 regulates conidiation, thermotolerance, apoptotic-like cell death and parasitism in the nematode endoparasitic fungus Hirsutella minnesotensis. Sci Rep 6; Article 30047

Javaid A, A Ali, A Shoaib, IH Khan (2021). Alleviating stress of Sclertium rolfsii on growth of chickpea var. Bhakkar-2011 by Trichoderma harzianum and $T$. viride. $J$ Anim Plant Sci 31 https://doi.org/10.36899/JAPS.2021.6.0378

Joshi D, P Singh, AK Singh, RJ Lal, N Tripathi (2016). Antifungal potential of metabolites from Trichoderma spp. against Colletotrichum falcatum went causing red rot of sugarcane. Sugar Technol 18:529-536

Kalaimani T (2000). Pathogenic variability of red rot caused by Colletotrichum falcatum Went. in Tamil Nadu. Ind Sugar 49:841-846

Khan A, M Awais, W Raza, A Zia (2011). Identification of sugarcane lines with resistance to red rot. Pak J Phytopathol 23:98-102

Khan IH, A Javaid (2020). In vitro biocontrol potential of Trichoderma pseudokoningii against Macrophomina phaseolina. Intl J Agric Biol 24:730-736

Khan IH, A Javaid, D Ahmed (2021). Trichoderma viride controls Macrophomina phaseolina through its DNA disintegration and production of antifungal compounds. Intl J Agric Biol 25:888-894

Kim YS, JG Song, IK Lee, WH Yeo, BS Yun (2013). Bacillus spp. BS061 suppresses powdery mildew and gray mold. Mycobiology 41:108-111

Kotasthane AS, T Agrawal, NW Zaidi, US Singh (2017). Identification of siderophore producing and cynogenic Pseudomonas fluorescent and a simple confrontation assay to identify potential bio-control agen for collar rot of chickpea. 3Biotech 7:137-144

Kumar N, T Jhang, Satyavirm, TR Sharma (2010). Molecular and Pathological characterization of Colletotrichum falcatum infecting subtropical Indian sugarcane. J Phytopathol 159:260-267

Landa BB, A Hervas, W Bettiol, RM Jimenez-Diaz (1997). Antagonistic activity of bacteria from the chickpea rhizosphere against Fusarium oxysporum f. spp. ciceris. Phytoparasitica $25: 305-318$ 
Menossi M, MC Silva-Filho, M Vincentz, MA Van-Sluys, GM Souza (2008). Sugarcane functional: Gene discovery for agronomic trait development. Intl J Plant Genomics 2008; Article 458732

Mwaheb MA, M Hussain, J Tian, X Zhang, MI Hamid, NA El-Kassim, GM Hassan, M Xiang, X Liu (2017). Synergetic suppression of soybean cyst nematodes by chitosan and Hirsutella minnesotensis via the assembly of the soybean rhizosphere microbial communities. Biol Cont 115:85-94

Pang F, T Wang, C Zhao, A Tao, Z Yu, S Huang, G Yu (2016). Novel bacterial endophytes isolated from winter wheat plants as biocontrol agent against stripe rust of wheat. Biocontrol 61:207-219

Perneel M, J Heyrman, A Adiobo, K De Maeyer, JM Raaijmakers, PD Vos and M Hofte (2007). Characterization of CMR5c and CMR12a, novel fluorescent Pseudomonas strains from the cocoyam rhizosphere with biocontrol activity. J Appl Microbiol 103:1007-1020

Prathima PT, M Raveendran, KK Kumar, PR Rahul, VG Kumar, R Viswanathan, P Balasubramaniam (2013). Differential regulation of defense-related gene expression in response to red rot pathogen Colletotrichum falcatum infection in sugarcane. Appl Biochem Biotechnol 171:488-503

Prittesh P, N Amaresan, S Rushabh, R Krishnamurthy, VV Bhasker (2016). Isolation and pathogenic variability of Colletotrichum falcatum causing red rot in sugarcane. J Plant Dis Prot 123:273-277

Raza M, ZF Zhang, KD Hyde, YZ Diao, L Cai (2019). Culturable plant pathogenic fungi associated with sugarcane in southern China. Fung Divers 99:1-104

Sambrook J, DW Russell (2001). Molecular Cloning: A Laboratory Manual

Sengar AS, KS Thind, B Kumar, M Pallvi, SS Gosal (2009). In vitro selection at cellular level for red rot resistance in sugarcane (Saccharum spp.). Plant Growth Regul 58:201-209

Sharf W, A Javaid, A Shoaib, IH Khan (2021). Induction of resistance in chili against Sclerotium rolfsii by plant growth promoting rhizobacteria and Anagallis arvensis. Egypt J Biol Pest Cont 31:16-26

Sharma PN, M Kaur, OP Sharma, P Sharma, A Pathania (2005). Morphological, pathological and molecular variability in Colletotrichum capsici, the cause of fruit rot of chillies in the subtropical region of north-western India. J Phytopathol 153:232-237

Shoaib A, H Ali, A Javaid, ZA Awan (2020). Contending charcoal rot disease of mungbean by employing biocontrol Ochrobactrum ciceri and zinc. Physiol Mol Biol Plants 26:1385-1397
Silva JAD, JA Bressiani (2005). Sucrose synthase molecular marker associated with sugar content in elite sugarcane progeny. Genet Mol Biol 28:294-298

Sun D, T Zhuo, X Hu, X Fan, H Zou (2017). Identification of a Pseudomonas putida as biocontrol agent for tomato bacterial wilt disease. Biol Cont 114:45-50

Tamura K, G Stecher, D Peterson, A Filipski, S Kumar (2013). MEGA6: molecular evolutionary genetics analysis version 6.0. Mol Biol Evol 30:2725-2729

Tewari S, NK Arora (2016). Fluorescent Pseudomonas spp. PF17 as an efficient plant growth regulator and biocontrol agent for sunflower crop under saline conditions. Symbiosis 68:99-108

Topalović O, M Hussain, H Heuer (2020). Plants and associated soil microbiota cooperatively suppress plant-parasitic nematodes. Front Microbiol 11; Article 313

Viswanathan R (2010). Plant Diseases: Red Rot of Sugarcane, pp:22-40. Anmol Publication Pvt. Ltd. New Delhi, India

Viswanathan R, P Malathi (2019). Biocontrol strategies to manage fungal diseases in Sugarcane. Sugar Technol 21:202-212

Viswanathan R, P Malathi, P Padmanaban (2003). Variation in sugarcane red rot pathogen Colletotrichum falcatum Went. In: Front Fungal Diversity in India, pp:639-667. International Book Distributing Co. Lucknow, Uttar Pradesh, India

Wang N, Y Zhang, X Jiang, C Shu, MI Hamid, M Hussain, S Chen, J Xu, M Xiang, X Liu (2016a). Population genetics of Hirsutella rhossiliensis, a dominant parasite of cyst nematode juveniles on a continental scale. Appl Environ Microbiol 82:6317-6325

Wang N, Y Zhang, M Hussain, K Li, M Xiang, X Liu (2016b). The mitochondrial genome of the nematode endoparasitic fungus Hirsutella rhossiliensis. Mitochondr DNA B 1:114-115

Wu B, M Hussain, W Zhang, M Stadler, X Liu, M Xiang (2019a). Current insights into fungal species diversity and perspective on naming the environmental DNA sequences of fungi. Mycology 10:127-140

Wu W, J Lei, M Hussain, S Cao, B Du, R Wang (2019b). Structure and function of the fruit microbiome in healthy and diseased kiwifruit. Pak J Agric Sci 56:577-585

Zhang W, C Hu, M Hussain, J Chen, M Xiang, X Liu (2019). Role of lowaffinity calcium system member Fig1 homologous proteins in conidiation and trap-formation of nematode-trapping fungus Arthrobotrys oligospora. Sci Rep 9; Article 4440 